\title{
PAUL RYAN, Paul Valéry, sous le signe de l'art et des artistes
}

\section{Fabio Scotto}

\section{(2) OpenEdition}

\section{Journals}

\section{Edizione digitale}

URL: https://journals.openedition.org/studifrancesi/45408

DOI: 10.4000/studifrancesi.45408

ISSN: 2421-5856

\section{Editore}

Rosenberg \& Sellier

\section{Edizione cartacea}

Data di pubblicazione: 1 août 2021

Paginazione: 398-399

ISSN: 0039-2944

\section{Notizia bibliografica digitale}

Fabio Scotto, «Paul ryan, Paul Valéry, sous le signe de l'art et des artistes», Studi Francesi [Online], 194 (LXV | II) | 2021, online dal 01 septembre 2021, consultato il 15 octobre 2022. URL: http:// journals.openedition.org/studifrancesi/45408 ; DOI: https://doi.org/10.4000/studifrancesi.45408

Questo documento è stato generato automaticamente il 15 octobre 2022.

\section{(2) $\Theta \Theta \Theta$}

Creative Commons - Attribuzione - Non commerciale - Non opere derivate 4.0 Internazionale - CC BY NC-ND 4.0

https://creativecommons.org/licenses/by-nc-nd/4.0/ 


\title{
PAUL RYAN, Paul Valéry, sous le signe de l'art et des artistes
}

\author{
Fabio Scotto
}

\section{NOTIZIA}

PAUL RYAN, Paul Valéry, sous le signe de l'art et des artistes, Paris, Lettres Modernes Minard, 2019, «Bibliothèque de lettres modernes» 52, 568 pp.

1 Già autore di studi su Valéry e il disegno e membro dell'équipe che ha curato l'edizione integrale dei Cahiers 1894-1914, Paul Ryan ci offre in quest'ampia e documentata monografia uno studio circostanziato sul rapporto fondamentale che il poeta di Sète ha intrattenuto con l'arte, dalle sue prime prove di pittore, fatte per lo più di ritratti e marine, alle riflessioni sulla pittura, i musei, l'architettura, l'edizione d'arte, la mondanità e la politica artistica, che ne caratterizzarono anche il ruolo pubblico. Strutturato in quattro parti, rispettivamente «Prémices d'une esthétique de l'art» (pp. 25-108), «Sous le signe du symbolisme» (pp. 111-256), «La famille et les peintres» (pp. 259-332), «Mondanités artistiques» (pp. 335-508), seguite da una «Conclusion» (pp. 509-517) e precedute da un'«Introduction» (pp. 13-21), il volume attraversa l'intero spettro della relazione di Valéry con l'arte, che, a ben vedere, coincide grossomodo con il periodo della Troisième République. Dalle iniziali pratiche amatoriali della pittura, che già palesano la sua predilezione per il disegno e la forma geometrica e ne faranno poi un ammiratore di Leonardo, modello di artista-scienziato, nell'Introduction à la méthode de Léonard de Vinci (1894), e di Degas (Degas danse dessin, 1938), il viaggio cui il libro invita è altresì lucida cronaca dell'attraversamento di una stagione particolarmente ricca e feconda dell'arte, dal tardo-simbolismo decadentista all'avvento delle avanguardie storiche primonovecentesche. Valéry, pur piuttosto indifferente alla pittura cosiddetta "moderna", tuttavia frequentò surrealisti come Breton e Dalì, ebbe relazioni strette con Marie Laurencin, collaborò con Picasso e fu in relazione con Vuillard, Matisse e Forain, ci ricorda Ryan (p. 21). 
2 A ragione, l'Autore rammenta quanto importante sia stato il legame matrimoniale con il lignaggio Morisot-Manet, cui si ricondusse ampia parte del movimento impressionista, il che faceva sì che in quell'ambiente $\mathrm{i}$ membri delle famiglie si passassero, per così dire, di padre in figlio/a rendite di posizione nel campo artistico (collezionisti, artisti), in un periodo dove peraltro era assai diffusa la pratica della poesia da parte degli artisti e viceversa, favorita dalle edizioni di libri illustrati. Il Valéry Presidente del Comité des arts et des lettres (1935), poi accademico di Francia svolgerà inoltre un'intensa attività di conferenziere (si veda a riguardo l'articolato panorama disegnato dai suoi testi sparsi raccolti nelle Pièces sur l'art, 1934), la cui carriera pubblica lo condurrà, come ben nota Ryan, a frequentare l'ambiente della mondanità artistica, fatta di vernissages, eventi vari, ma anche ateliers d'artisti, con i quali collaborerà a vario titolo, dalla Belle Époque fino alla guerra. Ricorrendo ampiamente alla ricca corrispondenza di Valéry, Ryan propone qui una riflessione approfondita che fonde il dato documentario con il substrato estetico del pensiero tale da consentire al lettore di cogliere, con la dovuta dovizia di informazioni e commenti, sempre coerenti e misurati, non solo il generale vissuto artistico di uno dei maggiori intellettuali della prima metà del secolo, ma anche le sue idee, spesso singolarmente in contro-tendenza rispetto all'epoca, teso com'era a vedere più in un'arte anche architettonica della difficoltà e del cimento "classico", piuttosto che negli sviluppi anamorfici di molta arte del suo tempo, la cifra più vicina all'investigazione del funzionamento del proprio intelletto che fu all'origine del vertiginoso progetto dei Cahiers. Chiudono il volume una vasta «Bibliographie» (pp. 519-537) e un «Index» (pp. 539-568). 